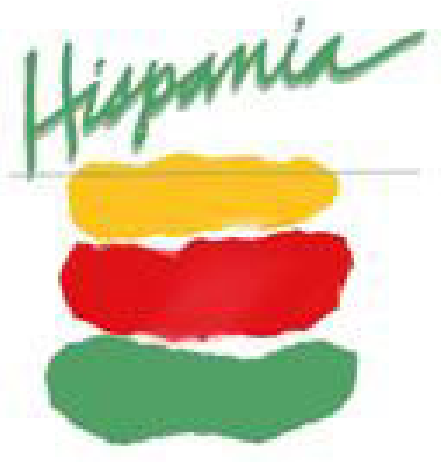

Valenciano y castellano. Actitudes lingüísticas en la sociedad valenciana

Author(s): José Luis Blas Arroyo

Reviewed work(s):

Source: Hispania, Vol. 77, No. 1 (Mar., 1994), pp. 143-155

Published by: American Association of Teachers of Spanish and Portuguese

Stable URL: http://www.jstor.org/stable/344468

Accessed: 06/03/2012 11:47

Your use of the JSTOR archive indicates your acceptance of the Terms \& Conditions of Use, available at http://www.jstor.org/page/info/about/policies/terms.jsp

JSTOR is a not-for-profit service that helps scholars, researchers, and students discover, use, and build upon a wide range of content in a trusted digital archive. We use information technology and tools to increase productivity and facilitate new forms of scholarship. For more information about JSTOR, please contact support@jstor.org.

American Association of Teachers of Spanish and Portuguese is collaborating with JSTOR to digitize, preserve and extend access to Hispania. 
Prepared by John Lipski

\title{
Valenciano y castellano. Actitudes lingüísticas en la sociedad valenciana
}

\author{
José Luis Blas Arroyo \\ Universidad Jaume I, Castellón (España)
}

\begin{abstract}
Este artículo estudia las actitudes sociolingüísticas en una comunidad de habla valenciana, una región de España donde una porción considerable de la población habla tanto el castallano como el catalán. Los datos empíricos de esta investigación demuestran la progresiva dignificación del idioma indígena-el dialecto valenciano del catálán-en la actitud de los hablantes, especialmente cuando se comparan estos resultados con los obtenidos en estudios anteriores. No obstante, hay una relación estrecha entre el progreso social y cultural y el castellano, particularmente entre la clase sociocultural y económica más alta de la sociedad así como entre los hablantes monolingües del castallano, los cuales representan un porcentaje importante de la comunidad entera. Estos factores retardan una normalización más rápida del catalán en esta región, constituyendo un patrón sociolingüístico distinto del de la comunidad vecina catalana.
\end{abstract}

Key Words: bilingüismo, actitudes lingüísticas, lenguas en contacto, sociolingüística, catalán, valenciano, castellano

\section{Introducción}

El tema de las actitudes lingüísticas ha sido abordado en numerosas ocasiones en el análisis de la realidad social del lenguaje. Como se ha advertido alguna vez, las actitudes pueden contribuir poderosamente a la difusión de los cambios linguiísticos, a la definición de comunidades de habla, a la consolidación de los patrones de uso y de evaluación social y, en general, a una serie amplia de fenómenos estrechamente relacionados con la variación lingüística en la sociedad (Carranza 1982: 63). H.López Morales (1989: 2321) considera el estudio de éstas como un importante capítulo en el desarrollo de la moderna disciplina sociolingüística, por su papel decisivo, junto con la conciencia linguística, en la explicación de la competencia comunicativa de los hablantes. Entre nosotros, Alvar (1975 93) ha llamado también la atención sobre este asunto: "plantearse el problema de qué pueda ser una sociolingüística es, ante todo, enfrentarse con la cuestión del concepto que el hablante tiene de su propio instrumento linguístico."
El presente trabajo quiere contribuir con los datos que presentaremos a continuación al debate que sobre las actitudes linguísticas en contextos de bilingüismo social se ha venido desarrollando en España a lo largo de las últimas dos décadas (vid. Rojo 1981; Gimeno 1982; Torres 1988; Blas 1991). Para ello hemos tomado como objeto de estudio una comunidad de habla urbana del País Valenciano actual, región autónoma situada en la franja mediterránea de la península ibérica y en buena parte de cuyo territorio ${ }^{1}$ se produce una típica situación de contacto de lenguas, que la mayoría de los estudiosos califica de diglósica (Ros 1982; Mollà y Viana 1988). Las lenguas que coexisten en tales áreas son el español y el catalán en su realidad dialectal conocida comúnmente como valenciano.

La comunidad elegida corresponde al distrito de Campanar, barrio situado al oeste de la ciudad de Valencia y, a nuestro juicio, especialmente atractivo para una descripción del bilingüismo social por su particular estructura demográfica, ya que en él conviven junto a un grupo importante de valencianohablantes originarios, otro con- 
tingente, también muy numeroso, de inmigrantes de habla castellana. Campanar, al igual que otros barrios periféricosBenimaclet, Benimamet ...-fue primitivamente un municipio independiente, anexionado por la ciudad de Valencia a finales del siglo XIX. Por otro lado, la heterogeneidad demográfica a la que aludimos tiene también un reflejo claro en la configuración urbanística del distrito. Así, gran parte de la población valencianohablante reside en el antiguo "pueblo" de Campanar, con su arquitectura característicamente rural, aunque hoy materialmente encerrada entre una nube de edificios modernos donde vive el resto de la población. Se trata, por otro lado, de un barrio en continua expansión desde hace dos décadas, al que se han desplazado en los últimos años numerosas familias de clase media, así como trabajadores de algunos importantes centros comerciales y de servicios de la ciudad.

La muestra se compone de 196 individuos residentes en el mencionado distrito desde al menos los dos años anteriores a la realización del estudio. Además de las variables de adscripción linguística-lengua materna y lengua dominante o habitual ${ }^{2}$ y lugar de origen ${ }^{3}$, hemos distribuido la población encuestada según diversos parámetros sociales, habituales en los trabajos sociolingüísticos y de sociología del lenguaje. Éstos son:

- la sexo: hombres (Hom)/mujeres (Muj)

- la edad: jóvenes (hasta 25 años) (Jov); adultos jóvenes (25-45 años) (Adj); adultos maduros (46-65) (Adm); ancianos (66 años en adelante) (Anc).

- el nivel de estudios. primarios incompletos; primarios completos; enseñanza secundaria; enseñanza superior.

- la escala socioeconómica. baja (C.Baj); media (C. Med); alta (C. Alt).

Entre los métodos de investigación sobre actitudes lingüísticas (vid. Silva Corvalán 1989), hemos elegido para la presente ocasión el cuestionario sociolinguíístico. A pesar de las dificultades que, como toda técnica plantea, este cuestionario es un instrumento muy conocido en el análisis del contacto de lenguas, que, entre otras, presenta la ven- taja considerable de su fácil distribución y ejecución (Dorian 1981: 157). En nuestro país ha sido ya utilizado en diversas ocasiones por el interés que sus datos pueden aportar para el estudio de numerosos aspectos relacionados con el bilingüismo peninsular (diglosia, tipos de bilingüismo social e individual, funciones y actitudes hacia las lenguas, grados de bilingüismo, etc.). Para este trabajo concretamente, hemos seguido las directrices del estudio pionero de Badia (1969) sobre la lengua de los barceloneses, seguida más adelante por otros autores, como Gimeno (1982) y Gómez Molina (1986).

Señalemos, por último, que la estructura de la investigación se atiene a las nociones creadas por Weinreich (1953/74), a las que anteriormente nos referíamos.

\section{Fidelidad lingüística}

Weinreich (1953: 9) define este parámetro actitudinal como la resistencia por parte de los hablantes a la pérdida de usos de su lengua o a los cambios en su estructura. En nuestro caso, y a través de una serie de preguntas relacionadas con el uso potencial del valenciano como vehículo de comunicación en ámbitos educativos ${ }^{4}$, valoramos la adhesión de los grupos sociolingüísticos bilinguies hacia esta lengua. Asimismo, pretendemos ofrecer una visión general de las actitudes que el conjunto de la población muestra hacia el cambio en las funciones sociales del valenciano. En el cuadro siguiente presentamos los resultados globales para cada uno de los ámbitos analizados:

$\begin{array}{llll} & \text { SI } & \text { NO } & \begin{array}{l}\text { INDIFE- } \\ \text { RENTE }\end{array} \\ \text { E.G.B } & 56.32 & 29 & 14.6 \\ \text { Ens. secund } & 50.56 & 28 & 21.34 \\ \text { Universidad } & 47.82 & 31.52 & 20.65\end{array}$

Total (conjunto poblac.) $51.56 \quad 29.53 \quad 18.86$

$1^{\circ}$ Estos resultados revelan una actitud positiva por parte del conjunto de la población acerca de la necesidad de normaliza- 
ción ${ }^{5}$ social del valenciano y su introducción en el ámbito educativo, terreno hasta hace poco reservado exclusivamente al castellano. No obstante, la proporción de los que se manifiestan contrarios no es despreciable (30\%), lo que introduciría en la sociedad un cierto elemento de rechazo.

$2^{\circ}$ Ahora bien, se observa una gradación descendente muy clara entre los niveles educativos más elementales, en los que las actitudes positivas son considerables, y el extremo opuesto, es decir, la enseñanza universitaria, donde la fidelidad linguiística de los informantes decrece. Parece, en consecuencia, que el valenciano no se considera globalmente tan apto para los estudios superiores, estudios que implican una mayor universalización del saber y que, por lo tanto, requerirían de una lengua más general. Por el contrario, en niveles inferiores, el valor potencial de la lengua autóctona como vehículo de comunicación docente se aprecia, en general, satisfactoriamente.

$3^{\circ}$ Por otro lado, la proporción de individuos indiferentes, aunque no muy elevada en términos absolutos, contribuye a ese bloque, que aproximadamente ocupa a la mitad de la población, y para el cual el uso del valenciano en estos ámbitos educativos superiores o no resulta interesante o es abiertamente hostil a sus deseos. Lo cual nos lleva a la conclusión de que, a pesar de un sentimiento mayoritario en favor de la dignificación social del valenciano, éste choca en nuestra comunidad de habla con una incomprensión todavía importante.

$4^{\circ} \mathrm{El}$ grupo de inmigrantes procedentes de regiones de habla castellana es el que se muestra más abiertamente opuesto a la normalización del valenciano en el ámbito educativo. Sus porcentajes negativos superan en todos los casos a las respuestas afirmativas, siguiendo además la gradación que comentábamos anteriormente, es decir, conforme avanzamos en la escala educacional, el recelo hacia la normalización del valenciano es mayor. Asimismo, en el ámbito universitario, la proporción de los hablantes de clase alta y monolingües en castellano que se niegan al reconocimiento del valenciano como lengua de cultura es también superior en términos absolutos.

$5^{\circ}$ En el resto de los casos, los porcentajes positivos son superiores a los negativos, si bien las diferencias entre los diversos grupos siguen siendo importantes, lo que indica también un distinto grado de lealtad hacia el valenciano. Los grupos que sobresalen siempre por su defensa de la normalización de la lengua autóctona en la educación son los siguientes:

- Mujeres

- Jóvenes y ancianos

- Estudios primarios y secundarios (sobre todo, estos últimos).

- Bilinguies valencianos y de lengua materna catalana.

- Nacidos en zonas de habla catalana (PVC).

No obstante, conviene señalar un matiz importante y es que dos grupos como los jóvenes y los hablantes con estudios primarios incompletos destacan también por unos índices altos de respuestas negativas, es decir, por su rechazo a la utilización del valenciano en la educación (conclusión: la indiferencia en ellos es muy escasa). Ello nos lleva a pensar que existen dos sectores muy diferenciados en el seno de cada uno de estos grupos. La división de pareceres es casi total, lo cual confirma la existencia de un importante contingente de este grupo generacional que se muestra hostil a la enseñanza en valenciano. Este hecho pudimos comprobarlo directamente a través de la conversación con jóvenes de $3^{\circ}$ de B.U.P. y C.O. $\mathrm{U}^{6}$ del Instituto de Campanar, algunos de los cuales-adheridos al castellano por lengua materna y habitual así como por su origen no valenciano-se mostraban muy contrarios a lo que, significativamente, consideraban "una pérdida de tiempo."

$6^{\circ}$ Asimismo, hay otra serie de grupos que se muestran mucho más reacios o, por lo menos, indiferentes a la introducción del valenciano en la educación. Destacan los siguientes:

-En general, los hombres manifiestan siempre unos índices mucho más bajos de respuestas positivas en relación a las mujeres

- Los hablantes generacionalmente adul- 
tos, tanto jóvenes como maduros. Mientras éstos últimos arrojan siempre las cifras de respuestas negativas más elevadas (en ocasiones notablemente, como el $40 \%$ que alcanza en los estudios universitarios), los hablantes situados entre los 25 y los 40 años superan a éstos en indiferencia hacia la cuestión. Es significativo que, salvo en el caso de la enseñanza básica, donde los porcentajes de actitud favorable al valenciano superan a la suma de los otros dos, en los otros niveles educativos (medios y universitarios) la relación se invierte. Por lo tanto, nos encontramos ante unos grupos generacionales en los que todavía se encuentran reticencias hacia la normalización del valenciano en la educación, especialmente en ámbitos superiores.

- Los hablantes de estudios superiores. El comportamiento de este grupo muestra claramente que, conforme avanzamos en la escala sociocultural, la actitud de fidelidad hacia el valenciano desciende. En este sentido, es preciso destacar que en el ámbito universitario también el grupo de enseñanza secundaria obtiene unos índices de rechazo elevados, lo que iría en consonancia con la regla comentada anteriormente, es decir, que conforme avanzamos en la jerarquía académica, el valenciano pierde fuerza como posible vehículo de comunicación.

- Algo similar puede decirse con respecto al grupo socioeconómico alto, el cual arroja siempre los índices más altos de respuestas negativas.

A la vista de estos últimos datos, se confirma claramente que los estratos socioculturales y económicos más elevados de la sociedad se muestran más reacios a aceptar la normalización del valenciano. Frente a ellos, los individuos situados en la escala media son los que manifiestan un mayor interés y apoyo hacia ésta.

- Los monolingües castellanos destacan también por un mayor recelo hacia el valenciano. Los porcentajes de respuestas negativas igualan o superan, en ocasiones, a las afirmativas, como es el caso del nivel de estudios universitarios. Asimismo, hay que destacar que entre los bilingües existe también una diferencia acusada entre los que poseen el valenciano como lengua habitual y quienes se expresan generalmente en castellano. Mientras los primeros superan la media de actitudes positivas en prácticamente todos los ámbitos, los bilingües castellanos manifiestan un comportamiento menos entusiasta, y especialmente-de nuevo-conforme vamos ascendiendo en la importancia de los estudios.

\section{El orgullo lingüístico}

Por medio de este rasgo (vid. Garvin y Mathiot 1956; Rubin 1968), deseamos conocer cuál es el grado de entusiasmo que los hablantes sienten por la lengua autóctona. Asimismo, nos interesa averiguar el nivel de presión social subjetiva que esta lengua ejerce sobre el conjunto de la sociedad y sobre los distintos grupos sociolinguíísticos. Por último, queremos investigar la actitud de los hablantes hacia el uso del valenciano en una serie de registros formales, especialmente importantes para la normalización de la lengua.

\subsection{Grado de orgullo}

Para la primera cuestión hemos tomado como indicador las respuestas a la siguiente pregunta, que fue formulada a todos los informantes: “ $¿$ Cree que los que residen de manera estable en Valencia deberían saber hablar valenciano?."

Dichas respuestas arrojan un índice moderadamente elevado de actitudes positivas (47.2\%), si bien el porcentaje de quienes se manifiestan contrarios no es desdeñable (26.37 \%), lo que unido a un nivel de indiferencia parecido, hace que para el conjunto de la sociedad, la presión subjetiva del valenciano no sea tampoco alta. Este reducido sentimiento respecto a la obligación de hablar el valenciano en las diferentes facetas de la vida cotidiana puede suponer un freno para la extensión social de la lengua autóctona, pues los grupos menos adheridos a esta lengua se sienten cómodos y seguros practicando exclusivamente el castellano.

Es muy significativo observar esta débil presión subjetiva en la comparación de los 
datos que ofrece este parámetro y los ya comentados en el epígrafe anterior. Si en aquella ocasión los hablantes adscritos a los grupos lingüísticos valencianos aventajaban claramente a los demás grupos (bilingües con lengua habitual y materna catalana), las distancias ahora son mucho más reducidas $\mathrm{y}$, en ocasiones, inexistentes. Se da, incluso, el caso de que el grupo de bilingües castellanohablantes habituales (56\%) aventaja ligeramente al de bilingües valencianohablantes (51.5\%). Asimismo, la lengua materna apenas discrimina a los hablantes en esta cuestión.

Acerca de este hecho sintomático, queremos recordar que en las conversaciones mantenidas con mumerosos bilingües nos llamó la atención observar cómo, mientras por un lado se manifestaban deseosos de la normalización social del valenciano, por otro se mostraban sumamente "respetuosos" con los deseos linguísticos de los demás, sobre todo con los de los inmigrantes.

No obstante, vuelven a sobresalir algunos grupos en su apoyo a la obligación de hablar valenciano en la sociedad:

- Las mujeres, con unas distancias porcentuales muy abultadas con respecto a los hombres.

-Estudios secundarios, superiores y primarios incompletos. Los primeros destacan no sólo por el índice más elevado, sino también por el porcentaje más bajo de respuestas negativas. Por su parte, vuelve a manifestarse una importante dicotomía entre los hablantes de estudios primarios. Sus porcentajes de actitudes positivas son altos $(52.1 \%)$, pero las negativas representan también a una parte importante de la población (40\%). La escasa incidencia, en este caso, de la adscripción linguística lleva a la conclusión de que ambos sectores responden a orígenes geográficos diferentes, perteneciendo el segundo -casi con toda seguridad-a los inmigrantes procedentes de zonas castellanohablantes.

-El grupo socioeconómico medio.

- Los bilingües.

- Los PVC. Este grupo no sólo destaca por su alto grado de actitud positiva, sino también por arrojar uno de los porcentajes más bajos en respuestas negativas (a diferencia, por ejemplo, de los hablantes nacidos en Valencia).

En el sentido contrario, destacan los grupos siguientes:

- Los hombres, cuyo porcentaje de respuestas negativas es similar al de respuestas positivas.

- Los adultos.

- Los hablantes con estudios primarios incompletos. Asimismo, los primarios completos arrojan el índice de actitud favorable más bajo de todos los grupos educativos, a considerable distancia de los demás. Es también uno de los que sobresalen por la indiferencia hacia esta cuestión.

-El grupo socioeconómico bajo.

- Los monolingües, grupo donde los porcentajes de respuestas afirmativas y negativas coinciden $(36.3 \%)$.

- Resto. Se trata del grupo más reacio a aceptar la obligación "moral" de hablar valenciano, sólo sentida por un $33.3 \%$, mientras el pensamiento contrario representa una cifra algo mayor $37.1 \%$, siendo también importante la indiferencia (29\%).

\subsection{Presión social subjetiva}

Para la evaluación del segundo aspecto, es decir, el entusiasmo que los hablantes manifiestan hacia el empleo del valenciano en determinados registros oficiales de especial relevancia, hemos utilizado dos parámetros:

- La oficialidad del valenciano en el ámbito público de la Comunidad Valenciana.

- El uso del valenciano en los medios de comunicación. Aquí se hizo especial referencia al empleo de dicha lengua en los canales autonómicos de radio y televisión.

Los resultados globales obtenidos en ambos contextos son los siguientes:

\section{¿Considera que debe hablarse valencia- no en los actos oficiales?.

SI NO INDIFERENTE

$52.8 \% \quad 22.5 \% \quad 24.7 \%$

Medios de comunicación.

SI NO INDIFERENTE

$53.3 \% \quad 30 \% \quad 16.6 \%$ 
Los resultados muestran algunos puntos en común, pero otros discrepantes que analizamos a continuación:

$1^{\circ}$ En primer lugar, destaquemos que la aceptación del valenciano en los dos contextos puede considerarse aceptable, pues abarca a algo más de la mitad de la población, con diferencias porcentuales muy leves entre ambos.

$2^{\circ}$ Sin embargo, el nivel de actitud negativa hacia el valenciano es mayor en lo que se refiere al uso de esta lengua en los medios de comunicación, alcanzando una cifra no desdeñable (30\%). Asimismo, las diferencias entre algunos grupos sociolingüísticos son muy importantes en esta cuestión, como veremos un poco más adelante.

$3^{\circ}$ Los hechos anteriores determinan que en la pregunta sobre el uso del valenciano en los medios de comunicación la indiferencia haya sido escasa, decantándose los informantes claramente hacia una de las dos opciones. Este hecho refleja un evidente interés por un ámbito sociológico que les es muy cercano, a diferencia de lo que ocurre con el uso del valenciano en los actos públicos, donde el nivel de indiferencia ha sido mayor.

$4^{\circ}$ Como decíamos en el párrafo anterior, el análisis de las preferencias por el uso del valenciano en los medios de comunicación ha deparado algunas discrepancias relevantes entre algunos grupos sociológicos. Así ocurre, por ejemplo, con el origen de los hablantes. Mientras los nacidos en zonas de habla catalana (Valencia y PVC) muestran un nivel muy alto de aceptación del valenciano, tan sólo un $20 \%$ de los inmigrantes procedentes de regiones de habla castellana (Resto) se muestra partidario de este uso, mientras un $56 \%$ se manifiesta abiertamente en contra. Algo similar ocurre también con

- ancianos

- hablantes de estudios primarios

- grupo socioeconómico bajo

mucho más reacios a la aceptación del valenciano como vehículo de comunicación de masas -en especial la televisión- que los demás grupos.

Asimismo, hay una serie de sectores de la comunidad en los que se produce también una fuerte división interna en torno al uso o no del valenciano en dichos ámbitos. Así ocurre con:

- los hombres, cuyo porcentaje de opiniones negativas supera incluso levemente a las afirmativas

- los hablantes adultos jóvenes

- los monolingüies llana.

- los hablantes de lengua materna caste-

$5^{\circ}$ Frente a estos grupos, hay otros que se decantan abiertamente por el uso del valenciano en los medios de comunicación. Sobresalen por ejemplo:

- las mujeres, con unos porcentajes absolutos muy elevados de actitud favorable y de los más bajos en la actitud contraria

- los jóvenes

- los estudios primarios, medios y superiores alto

- los grupos socioeconómicos medio y

- los bilingües, sobre todo valencianohablantes habituales

- los hablantes de lengua materna catalana

- los nacidos en Valencia.

Es interesante comparar el alto índice de aceptación positiva que muestran los estratos socioculturales y socioeconómicos elevados en comparación con la actitud mucho más recelosa mostrada en otros contextos. Quizá quepa interpretar en esta ocasión que dichos hablantes consideran el uso del valenciano en los medios de comunicación como un método ideal para la extensión y progresiva normalización de la lengua autóctona, sin acudir a otras medidas que perturben su cómodo asentamiento en el uso mayoritario del castellano. Parece, por ejemplo, que estos hablantes preferirían claramente que la lengua del canal autonómico de televisión fuera exclusivamente el valenciano, antes que la introducción de la misma en la educación, especialmente, como ya vimos, en niveles superiores donde el castellano seguiría siendo la principal lengua de comunicación y de cultura.

$6^{\circ}$ En líneas generales, la opinión sobre el uso oficial del valenciano en los actos 
públicos se acerca a la que acabamos de describir para los medios de comunicación. No obstante, hay algunas diferencias que es preciso comentar:

- Las diferencias cuantitativas entre los distintos grupos sociológicos, aun siendo importantes en algunos casos, decrecen ahora en términos generales. Este hecho traduce, probablemente, una menor oposición relativa a la consideración del valenciano como la lengua de los actos oficiales, en contraste con la que se manifestaba en el contexto de los medios de comunicación. Parece que el hecho de que el primero de los dominios sociales se sienta menos próximo a la vida cotidiana de estos hablantes sin duda, menos importante en la vida cotidiana que la televisión, por ejemplo-es determinante para esa rebaja en las diferencias porcentuales. Este hecho es significativo, por ejemplo en el grupo de los hombres, cuyas cifras de actitud favorable, aunque no muy importantes en términos absolutos -mucho menores, de nuevo, que las correspondientes al sexo opuesto- superan ahora claramente a las respuestas negativas.

-Otro hecho significativo es que el grado de indiferencia aumenta en la presente ocasión en casi todos los grupos sociológicos. En este sentido sobresalen:

- los hombres

- los adultos, tanto jóvenes como maduros.

- los hablantes de estudios primarios completos y los estudios superiores

-el grupo socioeconómico alto

- los bilingües con el castellano como lengua habitual

- los de lengua materna castellana

- otros orígenes.

Destaquemos, por el contraste que supone con el cuadro anterior, la presencia ahora de los estratos socioculturales y económicos altos entre los que arrojan los índices de indiferencia más elevados. No deja de ser significativo el hecho de que el grupo social más alto disminuya sus porcentajes de aceptación del valenciano en el caso de la oficialidad de la lengua autóctona, y que a la vez ascienda su indiferencia hasta un índice elevado como el $35 \%$. Insistimos nuevamente en que, a nuestro juicio, dichos estratos muestran una actitud más positiva hacia el valenciano en los ámbitos que menos afectan a su cómoda situación lingüística, más ligada al castellano.

\section{Utilidad lingüística}

Weinreich (1953) define este concepto como la necesidad que existe de una lengua para la comunicación social en una determinada comunidad de habla. Así pues, en el presente contexto nos interesa conocer cuál es el grado de utilidad que los hablantes de Campanar conceden a la lengua autóctona en distintos ámbitos de la vida social. Para ello nos ocupamos de comprobar:

- Cuál es la actitud de los hablantes de Campanar ante el uso del valenciano en algunas facetas de la vida social diaria (en el comercio, la calle, etc.).

- Cuáles son los ámbitos sociales preferidos por los hablantes para hablar valenciano ${ }^{7}$

- Si el interés por el aprendizaje del valenciano es creciente y por qué razones.

\subsection{Actitudes hacia el uso social del valencia- no}

A la primera cuestión, la mayoría de los hablantes respondió de una manera positiva (59.3\%), mientras los opuestos al uso del valenciano en la vida social diaria representaron un porcentaje escaso (13.2\%). Entre los primeros, destacaron por sus índices superiores a la media:

- las mujeres

- los jóvenes

- los estudios primarios completos y secundarios

-el grupo socioeconómico medio

- los bilingües, sobre todo los valencianohablantes habituales

- los hablantes de lengua materna catalana

- los nacidos en Valencia y PVC.

Aunque en todos los grupos sociales los porcentajes de actitud favorable superaron a los de la contraria, hubo algunos cuya aceptación del valenciano como lengua de 
uso diario fue más escasa, destacando, sobre todo

- los monolingües

- los inmigrantes procedentes de zonas de habla castellana.

\subsection{Dominios}

Respecto a la segunda cuestión, es decir, a los ámbitos preferidos por los bilingües para la comunicación en valenciano, digamos que, frente a un $41.8 \%$ que afirmaba hacerlo indistintamente con cualquier persona, la suma de los porcentajes restantes, relativos a ámbitos informales como la familia, los amigos, el trabajo, etc. suponía una cifra bastante más elevada (58.2\%), lo que a nuestro juicio viene a confirmar el carácter diglósico que el valenciano posee en esta comunidad. Es decir, la vinculación del uso del valenciano a los contextos más informales de la comunicación constituye una prueba más de que, para buena parte de la población, la lengua de la cultura y del progreso social sigue siendo el castellano.

No obstante, el porcentaje al que aludíamos en primer lugar no puede ser desdeñado sin más, pues revela, quizá, un avance en la dignificación social del valenciano respecto a épocas pasadas.

\subsection{Utilidad futura del valenciano}

Como ya hemos dicho, nos interesa finalmente conocer el grado de utilidad que los hablantes de Campanar conceden al valenciano en el futuro. Como se ha advertido en más de una ocasión, las aspiraciones económicas juegan un importante papel en la determinación de las actitudes de los individuos para el uso de la lengua (Rayfield 1970; 45). En nuestro caso, la aplicación progresiva de las leyes de fomento y uso del valenciano en la sociedad, y en especial, en los estamentos públicos, hace que cada vez más, la posesión de esta lengua vaya convirtiéndose en un importante estímulo para la promoción social. Por ello, además de investigar la opinión de los padres de familia acerca de la necesidad de que sus hijos aprendan el valenciano, importa saber qué motivos se aducen. El siguiente cuadro expresa los porcentajes obtenidos por cada una de las actitudes en el conjunto de la población

\section{MUCHO BASTANTE POCO NADA $36.1 \%$ $33.3 \%$ $16.6 \% \quad 13.9 \%$}

Como puede apreciarse, la actitud favorable de los padres hacia el aprendizaje del valenciano por parte de sus hijos puede ser considerada como importante $(69.4 \%)^{8}$. Sólo en el grupo de los inmigrantes procedentes de regiones de habla castellana (Resto), los porcentajes de actitudes negativas (56.5\%) superan a las positivas (43.5\%), aunque, como puede verse, esta última cifra es también moderadamente alta. Por el contrario, los demás grupos sociolinguiísticos, aunque en diferente medida, manifiestan un elevado deseo de que sus hijos aprendan valenciano.

Ahora bien, la segunda parte del análisis demuestra que las causas de tales actitudes son diferentes para los distintos grupos. Por un lado, una serie de ellos desean que sus hijos aprendan valenciano movidos por razones de carácter integrativo y emocional (vid. Ros y Giles 1979). Básicamente son dos

- porque es la lengua autóctona y por lo tanto es una obligación moral de los residentes en esta región el aprenderla

- porque con ello se conseguirá la normalización de una lengua que es patrimonio de todos y que es necesario potenciar.

En este sentido, los grupos que sobresalen son:

- las mujeres

- los adultos y ancianos

- los hablantes con estudios secundarios

- el grupo socioeconómico alto

- los hablantes adscritos lingüísticamente al valenciano (lengua materna y habitual).

Sin embargo, otros grupos destacaron por la expresión de causas relacionadas con la promoción social que antes mencionábamos. Para ellos, ya en la actualidad y a partir de ahora cada vez más, quien tenga la capacidad de expresarse correctamente en valenciano poseerá unas mayores oportunidades en el futuro mercado de trabajo de la 
Comunidad Valenciana, especialmente en los puestos de la administración pública. En este sentido sobresalieron grupos como

- los adultos jóvenes

- los hablantes de estudios primarios y superiores

- los grupos socioeconómicos bajo y alto

- los bilingüies castellanos.

\section{El rechazo lingüístico}

Entendemos por rechazo lingüístico el sentimiento negativo hacia una lengua (Torres 1977: 145). En este trabajo hemos medido tal actitud para cada una de las dos lenguas enfrentadas en nuestra comunidad de habla.

\subsection{Hacia el castellano}

Para medir este rechazo, hemos utilizado exclusivamente a los hablantes bilingües, pues era lógico pensar que los monolingües en castellano no expresarían actitud negativa alguna hacia su propia lengua.

Las respuestas al indicador utilizado (“¿Le molesta que le hablen en castellano?”), revelan que el sentimiento negativo hacia esta lengua es muy bajo. Tan sólo un $8.1 \%$ responde afirmativamente, mientras un porcentaje similar manifiesta que le molesta "un poco." Por el contrario, para el $83,4 \%$ restante, el sentimiento no es de hostilidad sino todo lo contrario. Las diferencias entre estas actitudes son de cierta consideración en algunos grupos, si bien hay, como siempre, algunos que destacan por sus mayores porcentajes. Los resultados demuestran que nuevamente hay un sector minoritario de la población que está tomando una decidida actitud de defensa y potenciación del valenciano, lo que se traduce ahora en una mayor hostilidad hacia la lengua que se considera rival. Con todo, los porcentajes de actitudes negativas obtenidos por estos grupos son bajos en términos absolutos, salvo quizá el de estudios secundarios, donde casi un $34 \%$ dice molestarse si le hablan en castellano. Dicho grupo parece demostrar a lo largo de este estudio una conciencia grande en torno a la necesidad de normalización del valenciano.
Por otro lado, es también significativo que determinados grupos-además, lógicamente, de los que tiene al castellano como lengua habitual y materna-como:

- hombres

- estudios superiores

- grupo socioeconómico alto no arrojen ni una sola respuesta negativa. Ya hemos visto en otras ocasiones cómo estos sectores de la población se caracterizan por una cómoda adhesión al castellano, en particular los estratos socioculturales más elevados. Por lo tanto, no es de extrañar que ahora manifiesten una actitud tan favorable hacia dicha lengua.

\subsection{Hacia el valenciano}

Hemos aprovechado como indicadores las respuestas a dos preguntas formuladas exclusivamente a los castellanohablantes. Las preguntas, así como los resultados globales de cada una de las respuestas, aparecen en los cuadros siguientes

\section{¿Le molesta que le hablen en valenciano? $\begin{array}{lll}\text { SI } & \text { NO } & \text { UN POCO } \\ 24.24 \% & 72.72 \% & 3.03 \%\end{array}$}

\section{¿Si alguna vez tiene dificultad, se esfuerza en entenderlo?

$\begin{array}{lll}\text { SI } & \text { NO } & \text { UN POCO } \\ 81.25 \% & 9.37 \% & 9.37 \%\end{array}$

Si atendemos al primer indicador, observaremos cómo la actitud positiva hacia el valenciano es también considerable; por el contrario, el sentimiento de rechazo alcanza una proporción más alta que la mostrada en el epígrafe anterior respecto a la otra lengua. En esta ocasión, el sector de la comunidad que manifiesta un sentimiento negativo hacia la lengua autóctona representa aproximadamente un $27.3 \%$. Además, obsérvese que tal rechazo es, por parte de algunos sectores de la población, más radical que el manifestado contra el castellano. Efectivamente, si allí comprobamos que los porcentajes se repartían a partes iguales entre las respuestas afirmativas sin paliativos y las más moderadas, en esta ocasión los hablantes que responden "un poco" ape- 
nas representan al $3 \%$ de la población, mientras el $24.2 \%$ restante responde mediante un "sí" sin paliativos. Lo cual es un prueba más de que, en el seno de la comunidad estudiada, la presión social que ejerce el valenciano no es fuerte, y que, por el contrario, en el conflicto entre ambas lenguas, son mayores las actitudes hostiles de los castellano-hablantes hacia el valenciano que al contrario.

Nos interesa saber ahora qué grupos sociales destacan por un mayor recelo hacia el valenciano, si bien hay que recordar nuevamente que estos datos son siempre relativos, pues prácticamente en todos los casos los porcentajes de rechazo son inferiores a los de la actitud contraria. Estos grupos son:

- los hombres

- los ancianos

- los estudios primarios incompletos y superiores

- el grupo socioeconómico alto

- Nacidos en la ciudad de Valencia . Es interesante subrayar la presencia de al menos un $25 \%$ de monolingües castellanos nacidos en Valencia que manifiestan una actitud hostil hacia el valenciano.

- Inmigrantes procedentes de regiones españolas de habla castellana.

Por otro lado, destaquemos nuevamente el comportamiento diferencial de diversos grupos en el seno de algunas variables sociológicas. Por ejemplo, los hombres (un $31.6 \%$ rechaza el que le hablen en valenciano), quienes nuevamente superan a las mujeres en su distanciamiento respecto a la lengua autóctona; o los grupos sociales más altos y de estudios superiores, con índices relativamente elevados también. La comparación entre el rechazo hacia las dos lenguas por parte de ambos grupos constituye una prueba más de la adhesión de estos estratos elevados de la sociedad hacia el castellano, así como de su inquietud ante un posible cambio de esquema sociolingüístico en nuestra comunidad de habla.

Las cifras del segundo indicador muestran que, incluso parte de los hablantes que se sienten molestos cuando se les habla en valenciano, se esfuerzan en entender si se presenta la ocasión, en lugar de exigir el cambio al castellano. Un porcentaje muy alto, el $81.2 \%$ responde afirmativamente a la cuestión planteada, mientras los hablantes reacios, total o parcialmente, sólo representan el $18.8 \%$ restante. Destacan como grupos menos dispuestos a realizar dicho esfuerzo

- los ancianos

- los hablantes de estudios primarios incompletos

- el grupo socioeconómico bajo.

En los dos primeros grupos, incluso, los porcentajes de rechazo superan claramente a la actitud positiva.

\section{Conclusiones}

Las actitudes de la comunidad de habla hacia la normalización del valenciano han sido por lo general positivas, como se desprende de los datos extraídos en una serie de ámbitos relevantes como la educación, los medios de comunicación, la administración pública y la vida social diaria. Asimismo, el rechazo global hacia dicha lengua es escaso.

No obstante esta actitud positiva alcanza sólo a una mayoría relativa de la sociedad, de manera que la dignificación social de la lengua autóctona se ve ensombrecida por una serie de indicadores, como los que resumimos a continuación:

$1^{\circ}$ En alguno de los ámbitos sociales más significativos, más de la mitad de la población se ha mostrado o bien abiertamente en contra de la normalización, o en el mejor de los casos, indiferente, hecho que, a nuestro juicio, puede suponer un freno considerable para la progresiva normalización social de la lengua autóctona.

$2^{\circ}$ En el ámbito educativo, hemos observado que el uso del valenciano se considera por lo general menos válido conforme ascendemos en la importancia de los estudios. Incluso, algunos grupos que se han destacado por su actitud positiva en términos globales-los jóvenes-se muestran más reacios a su uso como vehículo de comunicación en los niveles universitarios.

$3^{\circ}$ Algunos sectores influyentes de la 
sociedad, como los estratos económica y socialmente elevados, han manifestado poco entusiasmo hacia la recuperación social de la lengua autóctona. Asimismo, los inmigrantes procedentes de regiones españolas de habla castellana mantienen todavía un cierto recelo en torno a la normalización del valenciano.

A la vista de estos datos, cabe afirmar que el componente actitudinal de nuestra comunidad de habla, respecto a la situación de bilingüismo social que en ella se vive, es todavía claramente diglósico. En efecto, y al margen de los sucesivos matices e interpretaciones que ha sufrido desde su popularización en la obra de Ferguson (1959) (vid. Fasold 1984), el concepto de diglosia supone-para quienes lo aceptan-: "una situación en la que los miembros de una comunidad son conscientes de que las variedades intralinguiísticas o interlinguiísticas de sus repertorios están jerarquizadas; tienen conciencia también de que ninguna de esas variedades por sí sola, es suficiente para integrar socialmente a todos los miembros de tal comunidad" (Rotaetxe 1988: 60-61). $Y$ en la comunidad urbana de Campanar, parece que, en líneas generales, las funciones sociales instrumentales, esto es, las asociadas subjetivamente con el progreso socioeconómico y cultural siguen viéndose mayoritariamente del lado del castellano.

¿En qué medida la dignificación social de la lengua y la cultura autóctonas experimentada en los últimos tiempos puede contribuir al abandono de estos esquemas?. Como se ha advertido en numerosas ocasiones (Macnamara 1973), aunque la identificación con una lengua y su cultura y las actitudes positivas hacia ambas no son una garantía para el mantenimiento linguiístico, no puede negarse que constituyen un pilar fundamental para la rehabilitación de una lengua. Ningún esfuerzo institucional, por importante que fuera, obtendría éxito alguno si no viniera precedido por una actitud favorable hacia la normalización de la lengua por parte de la mayoría de la población. En este sentido, la distinción entre razones instrumentales e integrativas, utilizada inicialmente en la discusión teórica sobre el aprendizaje de segundas lenguas (vid. Gardner y Lambert 1972), puede resultar decisiva también para la configuración de modelos de mantenimiento o sustitución en diferentes partes del mundo (Baetens 1982 103). Ahora bien, frente a los planteamientos más tradicionales que ven en nociones integrativas, com la lealtad y el orgullo linguístico de los individuos, índices muy interesantes para la evaluación de las expectativas de normalización social de una lengua, algunos sociolingüistas han reaccionado últimamente poniendo de relieve la importancia superior de otros parámetros. En opinión de Mollà y Viana (1988: 27-28), se cae con demasiada frecuencia en el error de considerar el mantenimiento lingüístico como resultado de un acto de lealtad de los hablantes y, correlativamente, la pérdida como consecuencia de la renuncia voluntaria y consciente por parte de los usuarios. Aunque todo ello ocurre, en efecto, en algunos casos, son, a su juicio, los cambios globales, de carácter social, los que determinan el mantenimiento o la sustitución de las lenguas. Aun más, "la lealtad individual tiene una ínfima influencia en las sociedades modernas, de carácter urbano e industrial. Contrariamente, la difusión de una determinada lengua no está provocada siempre por factores de carácter nacionalista, sino más bien al contrario.(...) Una vez más, los valores instrumentales son los que determinan los hechos linguiísticos y no los valores de carácter simbólico (patriótico, nacional, etc.)."

En otro orden de cosas, hemos apreciado a lo largo de la presente investigación algunas diferencias significativas entre ciertos grupos sociales. En primer lugar, destacan aquellos sectores de la comunidad que han mantenido un comportamiento actitudinal más favorable a la normalización del valenciano. Así ha ocurrido sobre todo con

- las mujeres

- los hablantes de estudios secundarios

- los bilingües con el valenciano como lengua más habitual.

- los nacidos en zonas de habla catalana, con residencia actual en la ciudad de Valen- 
cia.

En el extremo opuesto, esto es, en la manifestación de una mayor recelo hacia la recuperación social de la lengua autóctona, han sobresalido, por el contrario

- los inmigrantes nacidos en zonas de habla castellana

- los hablantes monolingües, con el castellano como única lengua de comunicación.

- los estamentos socioeconómicos y culturales más elevados.

Estas diferencias permiten caracterizar relativamente bien a la sociedad de Campanar por lo que se refiere a las adhesiones linguiísticas. Parece, en efecto, que tanto la adscripción lingüística como el origen o el estatus social constituyen importantes índices para la estructuración sociolingüística de las actitudes en nuestra comunidad de habla.

\section{口 NOTAS}

${ }^{1}$ Aunque el catalán ocupa la mayor parte del territorio valenciano y, especialmente, las zonas más pobladas, no hay que olvidar que grandes áreas del interior de la actual Comunidad Autónoma Valenciana nunca lo han tenido como lengua propia. Las razones de tal disparidad estriban, como en tantos otros aspectos de la historia española, en las características específicas que la Reconquista tuvo en esas dos zonas, posteriormente integradas en el antiguo Reino de Valencia. De un lado, y procedentes en su mayoría del norte de habla catalana, un gran contingente de colonos se estableció en las tierras conquistadas desde el siglo XIII, preferentemente en las regiones costeras, dejando así una huella linguiística y cultural que perduraría hasta nuestros días. Por el contrario, las tierras del interior fueron reconquistadas en su mayoría por gentes del Reino de Aragón, de habla ya castellana desde hacia tiempo. La presencia de la lengua catalana en tierras valencianas es admitida sin concesiones por la comunidad científica, pero no así por parte de algunas instituciones pseudoculturales que alientan el espíritu secesionista de un buen número de valencianos. En opinión de estas gentes, el valenciano es una lengua romance, descendiente directa de los dialectos mozárabes hablados en la Edad Media, y por lo tanto, anterior a la impronta linguiística dejada por los colonizadores catalanes.

${ }^{2}$ Lengua materna: castellano (Cast)/catalán (cat.).

Lengua habitual o dominante: monolingües (castellanohablantes) (M. CAST)/bilingües con predominio del castellano (B. CAST)/ bilingües con predominio del valenciano (B. VAL).(Entre paréntesis aparece aquí, y en el resto de las variables, el código utilizado para el tratamiento informático y estadístico.

${ }^{3}$ Lugar de origen: Nacidos en la ciudad de Valencia (VAL)/Oriundos de otras regiones de habla catalana, tanto del País Valenciano como de otras áreas (Cataluña, Baleares, etc.) (PVC)/Inmigrantes de regiones de habla no catalana (RESTO).

${ }^{4 \prime C}$ Considera que debe utilizarse el valenciano como lengua de comunicación:

a) en la escuela (E.G.B): a) sí; b) no; c) indiferente

b) en el Bachillerato o Formación Profesional: a) sí; b) no; c) indiferente

c) en la Universidad: a) sí; b) no; c) indiferente.

${ }^{5}$ Entendemos el concepto de normalización en el sentido atribuido, entre nosotros, por Ninyoles (1975:123), esto es, la colocación en una plano de igualdad social y funcional de las lenguas en contacto dentro de una misma comunidad de habla. O lo que es lo mismo, la abolición del marco diglósico inicial. Advertimos esto para evitar la posible confusión con otras concepciones habituales en el marco de un sector de la sociolinguística catalana, como la que lleva a ver en la normalización la respuesta contraria a los procesos de sustitución lingüística en el contexto de las lenguas minorizadas (vid. Aracil 1982; Mollà y Viana 1988). Dicha normalización implica un cambio social de extraordinaria importancia que, entre otras cosas, supone caminar hacia el monolingüismo social, con el progresivo abandono de la lengua importada.

${ }^{6}$ Siglas que corresponden a los programas de enseñanza secundaria vigentes actualmente en España, a saber, Bachillerato Unificado Polivalente-tres cursos-y el Curso de Orientación Universitaria, respectivamente.

${ }^{7}$ Lógicamente esta cuestión irá dirigida exclusivamente a los hablantes bilinguies.

${ }^{8}$ Porcentaje obtenido tras la suma de las respuestas a "mucho" y "bastante."

\section{OBRAS CITADAS}

Aracil, LL. Papers de sociolingüística. Barcelona: La Magrana, 1982.

Alvar, M. "Actitud del hablante y sociolingüística." En AAVV. Teoría lingüistica de las regiones. Barcelona: Planeta, 1975.

Badia i Margarit, A. La llengua dels barcelonins. Resultat d'una enquesta sociológico-lingüistica. Barcelona: Edicions 62, 1969.

Baetens, B. Bilingualism: basic Principles. Clevedon Avon: Multilingual Matters, 1982

Blas, J.L. “Actitudes linguiísticas de los jóvenes valencianos hacia diversas variedades de español y catalán" en Actas del I Congreso Internacional sobre "El estudio del español," Salamanca (en prensa).

Carranza, M.A. "Attitudinal research on Hispanic language varieties.” En Bouchard, E. y Giles, H. (eds.). Attitudes Towards Language Variation. Social ans Applied Contexts. London: E. Arnold, 1982: 63-83.

Dorian, N. Language Death, The Life Cycle of a Scot- 
tish Gaelic Dialect. Philadelphia: U. of Pennsylvania $\mathrm{P}, 1981$.

Fasold, R. The sociolinguistics of society. Oxford: Basil Blackwell, 1984.

Ferguson, C. "Diglossia," Word 15 (1959): 325-40.

Gardner, R. y Lambert, W.E. Attitudes and Motivation in Second Language Learning. Rowley (Mass.): Newbury House, 1972.

Garvin, P. y Mathiot, M. "The Urbanization of the Guaraní Language: A problem in Language and Culture," 1956. En Fishman, J. (ed.). Readings in the Sociology of Language. The Hague: Mouton, 1968: 365-74.

Gimeno, F. “Alternatives al bilingüisme valencià merdional: A propòsit d'una preenquesta sobre les actitudes lingüistiques," Treballs de Sociolingüistica Catalana 4 (1982): 51-61.

Gómez Molina, J.R. Estudio sociolingüistico de la comunidad de habla de Sagunto (Valencia). Valencia: Institució Alfons el Magnánim, 1986.

López Morales, H. Sociolingüística. Madrid: Gredos, 1989.

Macnamara, J. "Attitudes and learning a second language," en Shuy, R y Fasold, R. W. (eds.). Language attitudes: Current Trends and Prospects. Washington, Georgetown UP, 1973.

Ninyoles, R. Estructura social y política lingüistica. Valencia: Fernando Torres, 1975.
Mollà, T. y Viana, A. Curs de Sociolingüística II. Alzira: Edicions Bromera, 1988.

Rayfield, J. The languages of a bilingual community. The Hague: Mouton, 1970.

Rojo, G. “Conductas y actitudes lingüísticas en Galicia," Revista Española de Lingüística 11.2 (1982): 269-310.

Ros, M. "Percepción y evaluación de los hablantes de cinco variedades lingüísticas," en Ninyoles, R. (ed.). Estructural social al País Valencià. València: Diputació Provincial, 1982: 679-98.

Ros, M. y Giles H. "The Valencian language situation: An accommodation perspective," ITL: Review of Applied Linguistics 44 (1979): 3-24.

Rotaetxe, K. Sociolingüística. Madrid: Síntesis, 1988.

Rubin, J. National bilingualism in Paraguay. The Hague: Mouton, 1968.

Silva Corvalán, C. Sociolingüistica: teoría y análisis. Madrid: Alhambra, 1989.

Torres, J. “Les enquestes sociolingüistiques catalanes del 1974 al 1984," TSC 7 (1988): 57-77.

Weinreich, U. Languages in contact. The Hague: Mouton, 1953. Trad. castellana: Lenguas en contcato. Descubrimientos y Problemas. Ediciones de la Biblioteca de la Universidad Central, Caracas, 1974. 